\title{
How to write a scientific masterpiece: an update for 2019
}

\author{
Ushma S. Neill \\ Editor at Large, Journal of Clinical Investigation, Ann Arbor, Michigan, USA.
}

M ch has changed in the scientific publishing realm since I last weighed in on how best to approach writing a scientific manuscript with maximal impact. While many of the fundamentals to creating a scientific masterpiece have remained the same, it is an excellent time to revisit what works best. Accompanying this short update is a video outlining the entirety of my suggestions on how to approach scientific publishing.

Earlier advice about items to consider before writing or submitting remains unchanged (1), including guidance on how to best pitch a cover letter (critically, remember to address the cover letter to the right journal), authorship concerns, and writing the actual text (covered at length in the accompanying video; https://www.jci.org/posts/591). But a few salient points should be updated for 2019, especially around steps to take before and after submitting.

\section{Before you submit your manuscript}

Target the right journal. Before you pick a journal to which you will send your work, it's important to understand the different kinds of journals. Within the basic science literature, there are essentially two different kinds of journals: those run entirely by professional editors and those run by an academic editorial board. The Nature, Cell, and Science families of journals are largely run by editors who are scientists who have finished a $\mathrm{PhD}$ and postdoc, have moved into being editors as their full-time positions, and are no longer involved in active laboratory research. Journals run by societies are often run by an academic editorial board, wherein those who handle the manuscripts are practicing physicians and scientists with active laboratory programs; these individuals handle manuscripts for a journal as an additional responsibility. This distinction becomes important as you pitch your cover letters at the right audience and when you consider the sort of reception you will get. How can you tell? Check the masthead, the list of those involved in the journal, and you will be able to check names - if you see names of laboratory heads and those actively publishing, it's likely an academic editor-led journal. If the publications you find for the editors listed are largely in the journal where they're listed as editor, it's likely a journal run by professional editors. Note there are a number of professional editors who support academic editor-helmed journals, so there can also be hybrid approaches. Furthermore, it's important to note whether the funding organization that supports your research mandates whether you publish in open/ free-access journals; you can also find out this information on journal websites. It is also critical to keep in mind the scope of the journal and the sort of articles that are usually published there - just as you would not naturally opt to send animal model-based work to a clinical journal, you should consider whether a journal is disease focused, whether it welcomes in vitro work or opts largely for in vivo, and how much it requires mechanistic information.

Presubmission inquiries. As you are considering your choices of where to publish and determining what is the right journal home for your work, consider using a presubmission inquiry. A "presub" is a cover letter and abstract (no more) that describes your work in order to give the editors an opportunity to give you a nonbinding thumbs up or down on whether they'd like to read the whole manuscript. You can submit your entire manuscript to only one journal at a time, but you can send a presub to 15 journals at a time and determine your best option. Often, you'll hear back from presubmission inquiries in much shorter order; however, note that solicitation to submit is not a promise that the journal will send the work out for full peer review. Note that some fellow journal editors have expressed that they do not appreciate presubs and prefer to read entire manuscripts, so perhaps only submit presubs if you have a rapport with an editor, as they may be more welcoming to evaluating a presub rather than a full submission.

Preprints. The most massive change in the scientific publishing landscape has been the embrace by the biomedical community of preprint servers. The most popular of these servers for biomedicine has been the bioRxiv (2), which hosts preliminary versions of scientific articles before submission to (or during) peer review. Through the posting of a preprint, authors can make their findings immediately available and can receive feedback on draft manuscripts before they are submitted to journals. The bioRxiv also allows submission to almost 150 journals directly from their site. If you do choose to post your article before peer review submission, simply indicate as much in a cover letter. Preprints can now also be cited in NIH grant applications (3).

Supplemental data. A massive change in the last 12 years since we last wrote about scientific publishing has been the explosion in supplemental data. In the December 2007 issue in which the original piece ran with advice on drafting scientific masterpieces, $58 \%$ of all manuscripts had supplements, with an average size of 0.9 MB. In the issue published while drafting this article (March 2019), 97\% had supplements (some with multiple files) with an average size of $5 \mathrm{MB}$. Furthermore, in looking at the statistics on readership, we note that in March 2019, the JCI website got 2.1 million clicks on all content; 24,425 of those clicks went to supplemental data 
files. This amounts to $1.2 \%$ of all attention going to supplements. While our advice is to include supplements when needed, you may also have some luck sneaking the rules for cribbage into your supplements, as few are looking at them.

Authorship. Most journals will continue to shy away from giving explicit guidance on authorship order, leaving guidelines to individual institutions and to the International Committee of Medical Journal Editors (4), who have provided concrete recommendations about what merits authorship versus acknowledgement. Many journals have seen an uptick in the number of shared first authorships, and recently, the JCI editors have reflected on whether there is bias in apportioning equal credit (5) and now require a rationale for the order in which shared first authors are listed.

\section{After you've submitted}

Postacceptance process. All journals require high-resolution versions of your figures for printing. Most journals are now screening all these figures for veracity, given how many times editors have found flaws that led to a cloud of suspicion over all data (6). It is never worthwhile to cheat, and you will get caught. Be prepared to substantiate your findings.

Also, be prepared to discuss your work in online venues; the scientific and biomedical community has embraced Twitter in recent years, and it is often the way many find out about new work in their areas. As an author, adding commentary online provides additional eyeballs on your work and an opportunity to engage with your peers. It can also be a welcome spotlight for trainees to get noticed for their hard work.

Rebuttals. Every author is entitled to further understand the reasons for rejection. The JCI - and many other journals - makes great efforts to customize deci- sion letters and to further explain reasoning when requested. Having said that, authors do need to recall that honey will catch more flies than vinegar, and a kindly stated request for clarification and reconsideration will always land better than a screed about how the editors are idiots or tantamount to trained monkeys (I have been called both). Furthermore, realize that the editors understand and set their own editorial bar, and it can be difficult to surmount the challenge if an editor replies that the manuscript was not considered to be appropriate for the scope of the journal.

If your appeal is on a manuscript that has been reviewed, there can often be an art to the reply to the editors and referees. Always recall that reviewing manuscripts is a gratis activity, and the reviewer on the other end is a peer; start with a comment expressing appreciation for the time the referee has taken to help you improve your manuscript and solidify the science. Attacks are not going to get you very far. Oftentimes, the referee is unaware of prevailing literature or a confounding factor, and you can gently point this out. The most genius approach I've seen with regard to how to politely make this point to a referee was, "...We would like to ask for a clarification. As we believe we have replied to all the comments from both reviewers and included them in the revised version, we are concerned that a misunderstanding might have occurred, acknowledging this may be due to poor communication on our part." You very likely communicated it just fine the first time, but this gives the referee an out and everyone can move on to the next point.

Reviewing for a journal. The topic of what to provide in a review has been covered elsewhere $(7,8)$, but a few updates to those previous pieces are also worthwhile. Both open peer review and double- blind peer review have become popular as options. Even when evaluating manuscripts in a blinded peer review process, please write your review as though you could be identified; kindness counts in reviewers just as much as in authors. Length of reviews is not commensurate with quality. Sometimes the most effective reviews are but a few sentences. Confidential comments can often help set the stage for an editor.

Address correspondence to: Ushma S. Neill, Journal of Clinical Investigation, P.O. Box 7226, Ann Arbor, Michigan 48107, USA. Phone: 646.888.2011; Email: usneill@the-jci.org.

1. Neill US. How to write a scientific masterpiece. J Clin Invest. 2007;117(12):3599-3602.

2. Learn JR. What bioRxiv's first 30,000 preprints reveal about biologists. Nature News. January 22, 2019. https://doi.org/10.1038/d41586-01900199-6. Nature website. https://www.nature. com/articles/d41586-019-00199-6. Accessed May 17, 2019.

3. Kaiser J. NIH enables investigators to include draft preprints in grant proposals. Science. March 24, 2017. https://doi.org/10.1126/science.aal0961. Science website. https://www.sciencemag.org/ news/2017/03/nih-enables-investigatorsinclude-draft-preprints-grant-proposals. Accessed May 17, 2019.

4. Defining the Role of Authors and Contributors by the International Committee of Medical Journal Editors. ICMJE website. http://www.icmje. org/recommendations/browse/roles-andresponsibilities/defining-the-role-of-authorsand-contributors.html. Accessed May 17, 2019.

5. Casadevall A, Semenza GL, Jackson S, Tomaselli G, Ahima RS. Reducing bias: accounting for the order of co-first authors. J Clin Invest. 2019;129(6):2167-2168.

6. Williams CL, Casadevall A, Jackson S. Figure errors, sloppy science, and fraud: keeping eyes on your data. J Clin Invest. 2019;129(5):1805-1807.

7. Turka LA. After further review. JClin Invest. 2009;119(5):1057.

8. Neill US. How to write an effective referee report. JClin Invest. 2009;119(5):1058-1060. 